\title{
Classificação citológica dos linfomas caninos
}

Sara Maria de Carvalho e SUZANO ${ }^{1}$

Julio Lopes SEQUEIRA ${ }^{2}$

Noemi Sousa ROCHA ${ }^{2}$

Adriana Wanderley de Pinho

PESSOA $^{3}$

\section{Correspondência para:}

Sara Maria de Carvalho e Suzano,

Rua Dois de Dezembro, 72 ap. 805

Flamengo, Rio de Janeiro - RJ, 22220-

040

smsuzano@uol.com.br

Recebido para publicação: 03/04/2007 Aprovado para publicação: 29/10/2009

\author{
1- Curso de Medicina Veterinária da Universidade Castelo Branco, Rio de \\ Janeiro-RJ \\ 2- Departamento de Clínica Veterinária da Faculdade de Medicina \\ Veterinária e Zootecnia da Universidade Estadual Paulista, Botucatu-SP \\ 3- Curso de Medicina Veterinária da Universidade Estadual do Ceará, \\ Fortaleza-CE
}

\section{Resumo}

Palavras-chave:

Os linfomas estão entre as neoplasias mais frequentes na espécie canina. Do ponto de vista etiológico, epidemiológico, clínico, morfológico e imunofenotípico, os linfomas caninos apresentam muitas semelhanças com os linfomas não-Hodgkin humanos e os esquemas de classificação destes têm sido utilizados na espécie canina. $\mathrm{O}$ objetivo do presente trabalho foi aplicar aos linfomas caninos as classificaçóes de Kiel, Working Formulation e Fournel-Fleury et al. (1994), em material colhido pelo método da PAAF (Punção Aspirativa por Agulha Fina). De acordo com a Classificação de Kiel, 61,02\% (36 casos) das neoplasias se enquadram como de grau alto 38,98\% (23 casos) como de grau baixo. Segundo a Classificação da Working Formulation, 11,86\% (sete casos) foram classificados linfomas de grau baixo, 61,02\% (36 casos) de grau intermediário e 27,12\% (16 casos) de grau alto. Utilizando a classificação proposta por Fournel-Fleury et al. (1994), 38,98\% (23 casos) dos animais que apresentaram linfomas de grau baixo e 61,02\% (36 casos) de grau intermediário ou alto. Concluindo, a PAAF é um método de diagnóstico que pode ser empregado na classificação dos linfomas caninos. A classificação que mostrou melhores resultados foi a de Kiel, que tem por característica principal a ênfase nos achados citológicos.

\section{Introdução}

Os linfomas estão entre as neoplasias mais frequentes na espécie canina ${ }^{1,2,3,4,5}$. Nesta espécie, sua incidência é de seis a trinta casos em cada 100.000 cáes/ano, sendo maior que na espécie humana ${ }^{6,7,8}$. Ocorrem mais frequentemente em animais com idade entre 5 e 11 anos $^{9,10,11}$, não havendo predileção por sexo ${ }^{5,11}$. Na espécie canina, esta neoplasia é considerada multifatorial e ainda não foi confirmada a participação de agentes virais ou químicos no seu aparecimento ${ }^{3,12,13}$.
Os linfomas não-Hodgkin (LNH) do homem apresentam várias características em comum com os linfomas dos cáes, particularmente com relação à epidemiologia, etiologia, clínica, morfologia e fenotipagem. Graças a essas semelhanças, os esquemas para classificação morfológica propostas para os LNH - como as de Kiel e Working Formulation - são utilizadas com sucesso por diversos autores para diagnosticar os linfomas da espécie canina. De acordo com alguns autores as características morfológicas dos LNH do homem servem como base para o estabelecimento do prognóstico e de 
protocolos de tratamento ${ }^{14,15,16,17}$. No cão, o tipo celular determinado pela classificação de Kiel foi um importante fator prognóstico para indicar o tempo de remissão da doença em animais tratados, enquanto que a classificação dos linfomas pela Working Formulation teve maior importância com relação ao prognóstico do tempo de sobrevida desses animais. Assim, outros autores, afirmam que as similaridades do LNH nestas duas espécies são suficientes para utilizar a doença do cão como modelo experimental, permitindo o teste de terapias e procedimentos clínicocirúrgicos nestes animais, antes de sua utilização no homem ${ }^{3,7,18,19}$. Fournel-Fleury, Magnol e Guelfi ${ }^{20}$ propuseram um sistema de classificação citológica específico para os linfomas caninos. Entretanto, esse sistema está fundamentado nas classificaçóes descritas para os LNH humanos.

A punção aspirativa por agulha fina (PAAF) tem sido empregada, tanto no homem quanto nos animais, como método de diagnóstico de lesôes das mais diversas origens, inclusive neoplásicas ${ }^{11}$. As vantagens deste método estão relacionadas à rapidez do diagnóstico, ao baixo custo e à sua eficácia. Além disso, causa desconforto mínimo ao paciente, permitindo que se realizem múltiplas colheitas e amostragens em série, particularmente interessantes quando surgem resultados inconclusivos ou quando existe suspeita de recidiva da lesão ${ }^{21}$. No homem e no cão cada vez mais há estudos que empregam a PAAF para o diagnóstico deste tipo de neoplasia ${ }^{4,22,23,24,25}$. Nos casos de linfadenomegalia, este exame permite a diferenciação rápida entre processos reacionais benignos e neoplásicos ${ }^{26}$. Quando há suspeita de lesão ou alteração em órgãos internos, como vísceras abdominais ou torácicas, a PAAF também pode ser realizada com auxílio da ultrassonografia ${ }^{26}$. Segundo a literatura, existe uma excelente correlação entre os resultados obtidos pela PAAF e por biopsias, tanto na classificação morfológica como na imunofenotipagem dos linfomas ${ }^{25,27}$.
Os exames citológicos, particularmente a PAAF, apresentam como principal limitação, a impossibilidade de serem obtidos dados sobre a arquitetura da neoplasia. No entanto, nos linfomas dos cães, este tipo de exame tem sido aceito como uma eficiente técnica de diagnóstico, visto que a grande maioria dos tumores, nesta espécie, apresenta a forma difusa, sendo a forma folicular bastante rara ${ }^{25,28}$.

Diante do que foi exposto observa-se que as características citológicas dos linfomas são um fator importante na determinação do prognóstico e do tratamento destas neoplasias. O objetivo do presente trabalho foi realizar a classificação dos linfomas caninos, utilizando as classificaçóes de Kiel, Working Formulation e Fournel-Fleury, Magnol e Guelf ${ }^{20}$ em material colhido pelo método de PAAF.

\section{Materiais e Métodos}

Foram utilizadas as amostras citológicas obtidas de 59 cães previamente diagnosticados com linfoma por meio do método da PAAF, durante o período de maio de 2000 a julho de 2003.

$\mathrm{Na}$ maioria dos animais, as punções foram realizadas nos linfonodos periféricos que apresentavam linfadenomegalia ou em lesões palpáveis extranodais. Também foi utilizado, embora com menor frequência, material proveniente de lesóes em órgãos internos obtidos com o auxílio da ultrassonografia, bem como de efusão pleural.

As punções foram feitas, empregandose uma seringa descartável de plástico de 10 $\mathrm{mL}$ e uma agulha $30 \times 0,7 \mathrm{~mm}$ acopladas ao citoaspirador de Valeri. O material colhido foi fixado em álcool metílico durante cinco minutos e corado pelo método de Giemsa. As amostras citológicas foram observadas e classificadas por pelo menos dois avaliadores. Os tipos citológicos foram determinados de acordo com as classificaçóes de $\mathrm{Kiel}^{29}$ e Working Formulation ${ }^{30}$, utilizadas para os linfomas não-Hodgkin humanos e com a classificaçáo citológica proposta por FournelFleury para os linfomas caninos. 


\section{Resultados}

As amostras obtidas utilizando-se o método da PAAF foram de boa qualidade e com celularidade suficiente para permitir o diagnóstico e a classificação citológica do linfoma. A coloração dos esfregaços pelo método de Giemsa possibilitou a visualização das características celulares, principalmente da morfologia nuclear, do padrão de distribuiçáo da cromatina e dos nucléolos que são elementos importantes na determinação do tipo celular predominante.

Os resultados da classificação citológica de acordo com os critérios das classificaçóes de Kiel, da Working Formulation e de FournelFleury estão apresentados na tabela 1 .

Tabela 1- Classificação citológica de 59 casos de linfoma canino de acordo com as classificações de Kiel,Working Formulation e Fournel-Fleury, Magnol e Guelfi ${ }^{20}$

\begin{tabular}{cccc}
\hline Kiel & Working Formulation & $\begin{array}{c}\text { Fournel-Fleury, Magnol e } \\
\text { Guelfi }^{20}\end{array}$ & Número de casos \\
\hline Grau baixo & Grau baixo & Grau baixo & \\
Linfocítico & Linfocítico & Linfocítico & 7
\end{tabular}

\section{Grau intermediário}

$\begin{array}{cc}\text { Centrocítico } & \begin{array}{c}\text { Células Pequenas } \\ \text { Clivadas }\end{array} \\ \begin{array}{c}\text { Centrocítico-Centro- } \\ \text { blástico }\end{array} & \begin{array}{c}\text { Misto de Células } \\ \text { Pequenas e Grandes }\end{array}\end{array}$

Grau alto

Centroblástico

Grandes Células não
Clivadas

\section{Grau alto}

Imunoblástico
Linfoblástico

Imunoblástico

Linfoblástico

Anaplásico

\begin{tabular}{cc} 
Anaplásico & Anaplásico \\
\hline Total & \\
\hline
\end{tabular}

Quando se utilizou a classificação de Kiel predominaram os linfomas de grau alto de malignidade. Resultado semelhante ao encontrado quando se empregou a classificação proposta por Fournel-Fleury. A classificação da Working Formulation quando aplicada a esta série de neoplasias mostrou predominância dos linfomas de grau intermediário.
Centrocítico

8

Centrocítico-Centroblástico

8

Grau intermediário ou alto

Centroblástico 20
7

Pequenas Células Blásticas

Anaplásico

Para os linfomas de grau baixo de acordo com a classificação de Kiel foram identificados sete casos de Linfomas Linfocíticos, oito casos de Centrocíticos e oito casos do tipo Centrocítico-Centroblástico.

Os Linfomas Linfocíticos se caracterizavam pela presença de células pequenas e núcleos redondos e pequenos, 
cujo diâmetro era semelhante ao de uma hemácia. A cromatina mostrava padrão denso com pequenos agregados mais grosseiros, não sendo observados nucléolos. $\mathrm{O}$ citoplasma destas células era sempre escasso. Nos Linfomas Centrocíticos o tipo celular predominante caracterizava-se pelo seu tamanho pequeno e por possuir núcleo também pequeno e clivado, com aspecto irregular e cromatina densa. O citoplasma era sempre escasso. Este tipo de linfoma equivale ao Linfoma de Pequenas Células Clivadas na classificaçáo da Working Formulation, sendo considerado nesta classificação como linfoma de grau intermediário.

Os Linfomas CentrocíticosCentroblásticos eram constituídos por uma população celular bimórfica, na qual estavam presentes células pequenas com núcleo irregular ou clivado e células grandes com núcleos não clivados. As células pequenas tinham características semelhantes às do tipo centrocítico descrito anteriormente e as células grandes possuíam as características do tipo centroblástico que será descrito a seguir. Este tipo de linfoma equivale ao Linfoma Misto de Células Pequenas e Grandes na classificação da Working Formulation, sendo considerado nesta classificação como linfoma de grau intermediário.

Nos linfomas de grau alto pela classificação de Kiel foram identificados vinte casos de Linfomas Centroblásticos, sete Imunoblásticos, oito casos de Linfoma Linfoblástico e um Anaplásico.

Os Linfomas Centroblásticos se caracterizavam pela presença de células grandes, com núcleos de diâmetro equivalente a duas ou três hemácias, cromatina vesicular e nucléolos múltiplos e periféricos. As figuras de mitose eram frequentes. $\mathrm{O}$ citoplasma destas células podia ser escasso ou abundante. Este tipo de linfoma equivale ao Linfoma de Grandes Células não-Clivadas na classificação da Working Formulation, sendo considerado nesta classificação como linfoma de grau intermediário. Os Linfomas do tipo Imunoblásticos eram constituídos por células de tamanho médio ou grande, núcleo com diâmetro variando entre uma e meia a duas hemácias, cromatina vesicular e nucléolo proeminente e central. As figuras de mitose eram frequentes. O citoplasma era variável, anfófilo ou basofílico.

A composição celular dos Linfomas Linfoblásticos se caracterizava por células

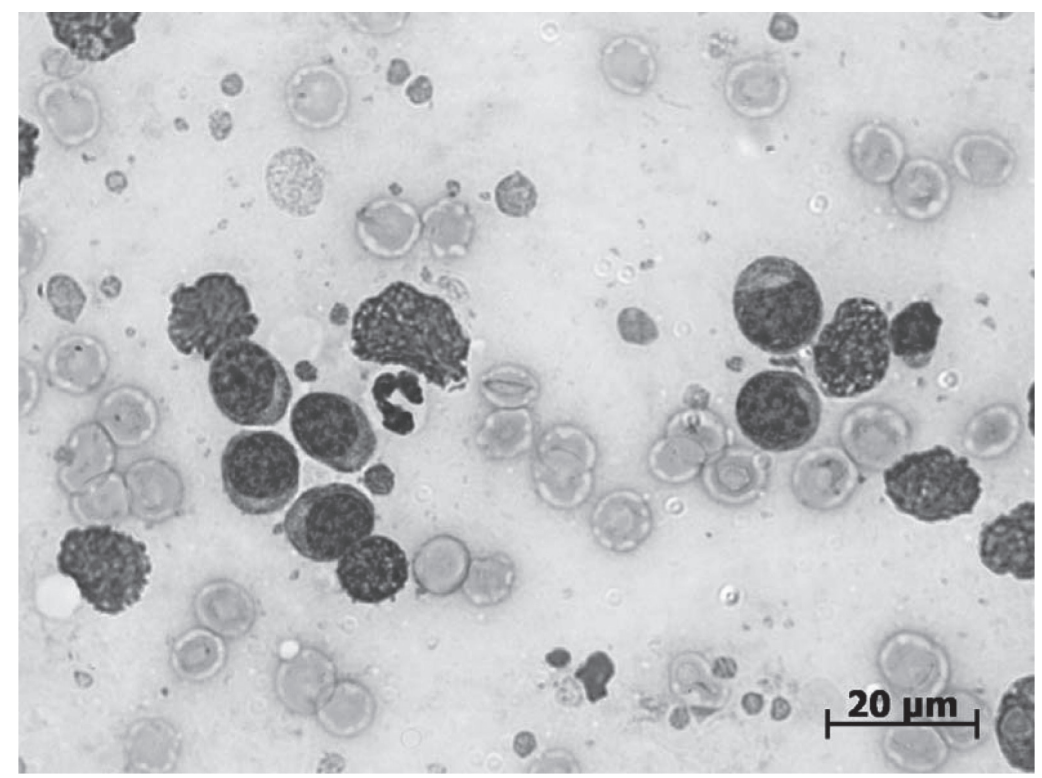

Figura 1- Linfoma Centroblástico (Kiel e Fournel-Fleury Magnol e Guelfi ${ }^{20}$ ), equivalente ao Linfoma de Grandes Células não Clivadas (WF). As células mostram nucléolos múltiplos, proeminentes e periféricos. Giemsa, 400X 


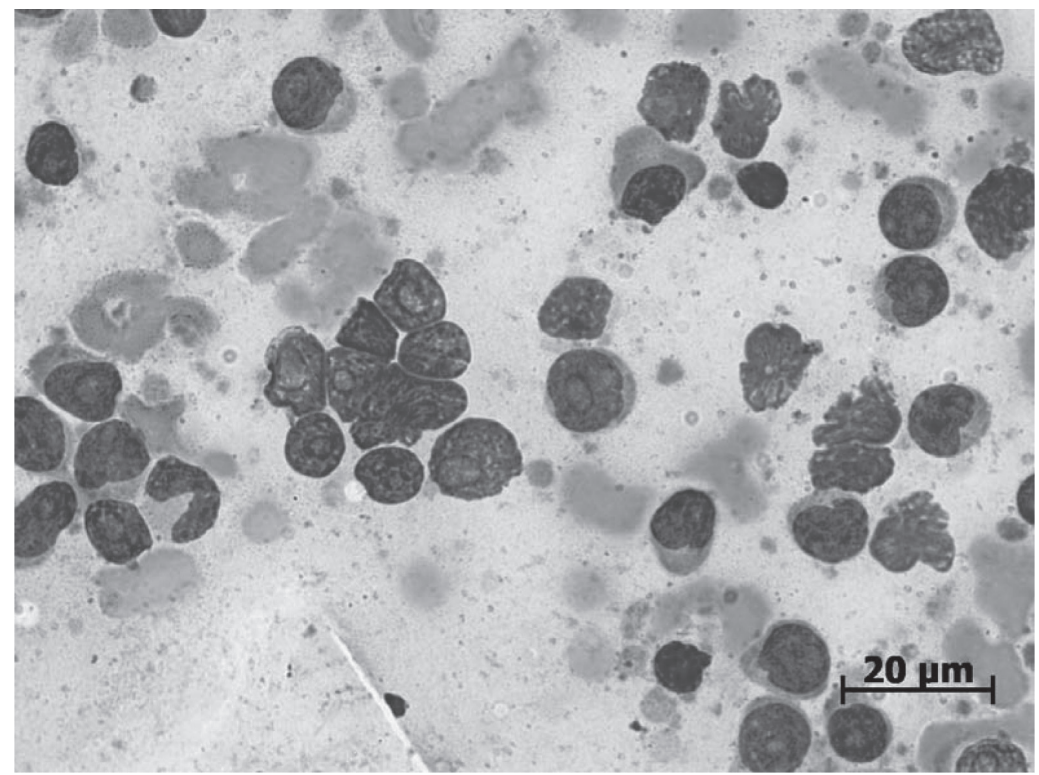

Figura 2- Linfoma Imunoblástico (Kiel e Fournel-Fleury et al. e WF), As células mostram nucléolo único, proeminente e central. Giemsa, 400X

pequenas, cujo núcleo equivalente a uma $\mathrm{e}$ meia hemácia, apresentava forma redonda ou oval. Nestas células a distribuiçáo da cromatina era uniforme, não permitindo a observação dos nucléolos. As figuras de mitose eram frequentes. $\mathrm{Na}$ maioria das células o citoplasma escasso e fracamente basofílico formava um anel ao redor do núcleo.

O Linfoma Anaplásico caracterizavase por apresentar uma populaçáo de células grandes pleomórficas, que possuíam núcleo grande e irregular, com cromatina fina ou granular e citoplasma claro ou levemente basofílico. O número de mitoses era sempre muito alto.

De acordo com a Classificação de Kiel, 61,02\% (36 casos) das neoplasias se enquadram como de grau alto de malignidade e 38,98\% (23 casos) como de grau baixo de malignidade. Segundo a Classificação da Working Formulation, 11,86\% (sete casos) dos animais apresentaram linfomas de grau baixo de malignidade, $61,02 \%$ (36 casos) de grau intermediário e $27,12 \%$ (16 casos) de grau alto. Utilizando a classificação proposta por Fournel-Fleury, Magnol e Guelfi ${ }^{20}$, $38,98 \%$ (23 casos) foram de linfomas de grau baixo de malignidade e $61,02 \%$ (36 casos) de grau intermediário ou alto.

\section{Discussão}

A punção aspirativa por agulha fina (PAAF) vem sendo utilizada na Medicina Veterinária por ser um método de diagnóstico eficaz, rápido e de baixo custo. Além dessas vantagens, não há necessidade de sedar o animal e permite que se realizem múltiplas coletas e amostragens em série, particularmente necessárias quando se observam resultados inconclusivos ou quando existe suspeita de recidiva da neoplasia ${ }^{21}$. Essa versatilidade da citologia aspirativa somada à rapidez com que as coloraçóes podem ser realizadas proporcionam aos clínicos diagnóstico rápido, seguro e definitivo na grande maioria das situaçôes ${ }^{20,29}$.

Um dos aspectos mais importantes do exame citopatológico é a fixação do esfregaço. Quando este procedimento não é realizado ocorre a distorção da morfologia celular. Segundo alguns autores, o artefato mais comum presente nos esfregaços não fixados é a alteração dos núcleos. No presente estudo, 
a fixação imediata dos esfregaços preservou a estrutura das células e permitiu a observação dos detalhes celulares mais importantes para cada classificaçáa ${ }^{4,28,30}$. Outros autores citam ser necessária a centrifugação das amostras colhidas, antes do preparo dos esfregaços, para se obter material mais rico em células. No presente estudo, não houve necessidade deste tipo de procedimento, já que a celularidade do esfregaço foi sempre muito alta ${ }^{11}$.

Vários autores utilizam as classificaçóes propostas para os linfomas não-Hodgkin do homem para diagnosticar os linfomas dos cães ${ }^{4,67,717,18,25,28}$. No entanto, na maioria dos estudos foi utilizado material incluído em parafina, sendo ainda poucos os trabalhos que empregam o exame citopatológico para este fim ${ }^{9,17,18,23,25,28}$. As características citomorfológicas encontradas nas amostras analisadas permitiram incluí-las facilmente nas categorias descritas para as diferentes classificaçóes de Kiel e Working Formulation, embora nem todos os tipos descritos em cada uma delas tenham sido encontrados neste trabalho.

No presente estudo, quando foi utilizada a classificaçáo de Kiel, predominaram os linfomas de grau al to $(61,02 \%)$ em relaçáo aos linfomas de grau baixo $(38,98 \%)$, resultado semelhante obtido por Teske e Van Heerder ${ }^{4}$, que utilizaram esta mesma classificação em material colhido pelo método da PAAF. O predomínio dos linfomas de grau alto se verifica mesmo quando a classificação de Kiel é aplicada ao exame histopatológico da neoplasia ${ }^{3,4,6,7,18,25,31}$. A classificação de Kiel se baseia, principalmente, em critérios citomorfológicos bem definidos, não dando ênfase ao padrão arquitetural da neoplasia. Portanto, torna-se o tipo de classificação ideal para ser empregada nos exames citopatológicos. Os Linfomas Centroblásticos $(33,9 \%)$ foram os mais frequentes em nossa casuística, resultado também obtido por diversos autores que utilizaram essa mesma classificação ${ }^{3,7,9,18,25,31}$.

A utilização da classificação da Working Formulation em nossa série de linfomas mostrou prevalência maior para os linfomas de grau intermediário $(61,02 \%)$, seguidos dos linfomas de grau alto $(27,12 \%)$ e dos linfomas de grau baixo $(11,86 \%)$, a mesma proporção foi obtida por Fournel-Fleury et al. ${ }^{18}$. O tipo citológico mais frequente foi o Linfoma de Grandes Células não-Clivadas (33,9\%). A literatura consultada indica diferença significativa na frequência dos tipos citológicos entre os diferentes autores que utilizaram esta classificação, tanto em exames citológicos como nos histológicos. O Linfoma de Grandes Células não-Clivadas é apontado como o mais frequente ${ }^{7,17,18,32}$. No entanto, para alguns autores, a prevalência maior foi para os Linfomas Imunoblásticos com $37,5 \%$ e $24,9 \%{ }^{6,28}$. No presente trabalho, este tipo de linfoma respondeu por 11,86\% dos casos. Essas diferenças, provavelmente, são reflexos da maior complexidade desta classificação e da necessidade da familiarização dos patologistas com os diferentes tipos citológicos que a compóem. Deve-se ter em mente que os linfomas no homem podem apresentar características regionais e que isto pode ocorrer também com a espécie canina, podendo este fato ser, ao menos em parte, responsável pelas discrepâncias observadas $^{28,30}$.

A classificação dos linfomas caninos proposta por Fournel-Fleury, segundo os próprios autores, representa simplesmente uma adaptação, embora pequena, da classificação de Kiel para esta espécie. Esta adaptação se justificaria, ainda segundo os mesmos autores, porque alguns linfomas seriam compostos por tipos celulares que não são observados nos linfomas humanos, como Linfoma Difuso de Células Médias Macronucleoladas. Nestes, as células são de tamanho médio, com núcleo pequeno ou médio, nucléolo proeminente, citoplasma moderadamente basofílico e baixo índice mitótico. Esta última característica associada ao tamanho pequeno das células incluiria este tipo entre os linfomas de grau intermediário ${ }^{18,20}$. $\mathrm{Na}$ casuística deste estudo, nenhum dos linfomas mostrou células com estas características. O presente trabalho 
permite concluir que a PAAF é um método de diagnóstico eficiente, simples e de baixo custo, que pode ser empregado com sucesso no diagnóstico e classificação citológica dos linfomas dos cães. Dentre as classificaçóes utilizadas no presente estudo a Classificação de Kiel foi a que apresentou melhor adequaçáo aos resultados por ser fundamentada nas características morfológicas das células.

\section{Agradecimentos}

À Fundação de Amparo a Pesquisa do Estado de São Paulo, pelo apoio financeiro (processo no 01/12045-1).

\title{
Cytological classification of canine lymphomas
}

\begin{abstract}
Lymphoma is among the most frequent canine neoplasia and share many similarities with human non-Hodgkin's lymphoma in respect of etiology, epidemiology, clinical, morphological and immunophenotipical aspects. Human classification schemes have been used in canine lymphoma. The aim of this work was apply Kiel, Working Formulation and Fournel-Fleury's et al. (1994) classification in Fine Needle Aspiration (FNA) cytology matherial. According to Kiel scheme $61.02 \%$ (36 cases) were high-grade lymphomas and 38.98\% (23 cases) low grade. The Working Formulation, showed $11.86 \%$ (7 cases) of low grade, $61.02 \%$ (36 cases) intermediary grade and $27.12 \%$ (16 cases) high grade. In Fournel-Fleury's protocol revealed a predominance of high-grade lymphoma, with $61.02 \%$ (36 cases) over $38.98 \%$ (23 cases) of low grade. In conclusion, FNA can be used as a diagnostic method and in canine lymphoma cytological classification. Kiel's system showed the best results, once is based on cytologic basis.
\end{abstract}

Keywords: Lymphoma. Cytology.

\section{Referências}

1 CAPURRO, C.; BURACCO, P.; ROSSI, L. Lymphoma in dogs. European Journal of Comparative Annimal Practice, v. 2, n. 2, p.15-29, 1992.

2 MILNER, R. J.; PEARSON, J.; NESPIT, J. W.; CLOSE, P. Immunophenotypic classification of canine malignant lymphoma on formalin-fixed paraffin wax-embedded tissue by means of CD3 and CD79a cell markers. Onderstepoort Journal of Veterinary Research, v. 63, n. 4, p. 309-313, 1996.

3 TESKE, E. Canine malignant lymphoma: A review and comparion whit human non-Hodgkin's lymphoma. Veterinary Quaternaly, v. 16, n. 4, p. 209-219, 1994.

4 TESKE, E.; VAN HEERDE, P. Diagnostic value and reproducibility of fine needle aspiration cytology in canine malignant lynfoma. Veterinary Quaternaly, v. 18, n. 3, p. 112-115, 1996.

5 VONDERHAAR, M. A.; MORRISON, W. B. Lymphosarcoma. In: MORRISON, W. B. Cancer in dogs and cats. Philadelphia: Williams \& Wilkins. 1998. p. 667-695.
6 APPELBAUM, F. R.; SALE, G. E.; STORB, R.; CHARRIER, K.; DEEG, H. J.; GRAHAM, T.; WULFF, J. C. Phenotyping of canine lymphoma with monoclonal antibodies directed at cell surface antigens: classification, morphology, clinical presentation and response to chemotherapy. Hematological. Oncology, v. 2, p. 151-168, 1984.

7 GREENLEE, P. G.; FILIPPA, D. A.; QUIMBY, F. W. Lymphoma in dogs: a morphologic, imunologic and clinical study. Cancer, v. 66, n. 3, p. 480-490, 1990.

8 JACOBS, R. M.; MESSICK, J. B.; VALLI, V. E. Tumors of the hemolymphatic system. In: MEUTEN, D. J. Tumors in domestic animals. 4. ed. lowa: lowa State Press, 2002. p. 19-198.

9 VALLI, V. E. O. The hematopoietic system. In: JUBB, K. V. F.; KENNEDY, P. C.; PALMER, N. Pathology of domestic animals. 4. ed. New York: Academic Press, 1993. v. 3, p. 149-153.

10 JONES, C. J.; HUNT, R. D.; KING, N. W. Veterinary pathology. 6. ed. Philadelphia: Williams \& Wilkins, 1997. p. 1009-1042. 
11 SNEIGE, N.; DEKMEZIAN, R. H.; KATZ, R. L.; FANNING, T. V.; LUKEMAN, J. L.; ORDONEZ, N. F.; CABANILLAS, F. F. Morphologic and immunocytochemical evaluation of 220 fine needle aspirates of malignant lymphoma and lymphoid hyperplasia. Acta Cytology, v. 34, n. 3, p. 311-322, 1990.

12 HAYES, H. M.; TARONE, R. E.; CANTOR, K. P. On the association between canine malignant lymphoma and opportunity for exposure to 2,4-dichlorophenoxyacetc acid. Environmental Research, v. 70, n. 2, p. 119-125, 1995.

13 GAVAZZA, A.; PRESCIUTTINI, S.; BARALE, R.; LUBAS, G.; GUGLIUCCI, B. Association between canine malignant lymphoma, living in industrial areas, and of chemicals by dog owners. Journal of Veterinary Internal Medicine, v. 15, n. 3, p. 190-195, 2001.

14 ASTER, J.; KUMAR, V. White cells, lymph nodes, spleen and thymus. In: COTRAN, R. S.; KUMAR, V.; COLLINS, T. Pathologic basis of disease. 6 . ed. Philadelphia: W.B. Sauders Company, 1999. p. 645-695.

15 MILITO, C. B.; MORAIS, J. C.; NUCCI, M.; PULCHERI, W.; SPECTOR, N. Classificação dos linfomas nãoHodgkin: estudo morfológico e imunoistoquímico de 145 casos. Journal of Brazilian Patology and Medicine. Laboratory, v. 38, n. 4, p. 315-324, 2002.

16 MELLANBY, R. J.; HERRTAGE, M. E.; DOBSON, J. M. Treatment of canine lymphoma by veterinarians in first opinion practice in England. Journal of Small Animal Practice, v. 43, n. 5, p. 198-202, 2002.

17 GUIJA DE ARESPACOCHAGA, A.; SCHWENDENWEIN, I.; WEISSENBOCK, H. Retrospective study of 82 cases of canine lymphoma in Austria based on the Working Formulation and immonophenotyping. Jounal of Comparative Pathology, v. 136, n. 2-3, p. 186-192, 2007.

18 FOURNEL-FLEURY, C.; MAGNOL, J. P.; BRICAIRE, P.; MARCHAL, T.; CHARBANNE, L.; DELVERDIER, A.; BRYON, P. A.; FELMAN, P. Cytohistological and immunological classification of canine malignant lymphomas: comparison with human non-Hodking's lymphomas. Journal of Comparative Pathology, v. 117, n. 1, p. 35-59, 1997.

19 FOURNEL-FLEURY, C.; PONCE, F.; FELMAN, P.; BLAVIER, A.; BONNEFONT, C.; CHABANNE, L.; MARCHAL, T.; CADORE, J. L.; GOY-THOLLOT, I.; LEDIEU, D.; GHERNATI, I.; MAGNOL, J. P. Canine Tcell Lymphoma: a morphological, immunological, and clinical study of 46 new cases. Veterinary Pathology, v. 32, n. 1, p. 92-109, 2002.

20 FOURNEL-FLEURY, C.; MAGNOL, J. P.; GUELFI, J. F. Color atlas of cancer cytology of the dog and cat. In: CONFERENCE NATIONALE DES VETERINARIES SPECIALISES EN PETITS ANIMAUX, 1994. Paris. p. 243-267.

21 VERNAU, K. M.; HIGGINS, R. J.; BOLLEN, A. W.; JIMENEZ, D. F.; ANDERSON, J. V.; KOBLIK, P. D. Primary canine and feline nervous tumors: intraopera- tive diagnosis using the smear technique. Veterinary Pathology, v. 38, n. 1, p. 47-57, 2001.

22 ROBEY, S. S.; CAFFETY, L. L.; BESCHORNER, W. E.; GUPTA, P. K. Value of lymphocyte marker studies in diagnostic cytopathology. Acta Cytology, v. 31, n. 4, p. 453-459, 1987.

23 DICKINSON, R. M. Canine lymphossarcoma: Overcoming diagnostic obstacles and introduction to the latest diagnostic techniques. Canadian Veterinary Journal, v. 49, n. 3, p. 305-306, 2008.

24 BALLEGEER, E. A.; FORREST, L. J.; DICKINSON, R. M.; SCHUTTEN, M. M.; DELANEY, F. A.; YOUNG, K. M. Correlation of ultrassonographic appearance of lesions and cytologic and histologic diagnoses in slenic aspirates of dogs and cats: 32 cases (2002-2005). Journal of American Veterinary Medical Association, v. 230, n. 5, p. 690-696, 2007.

25 SOZMEN, M.; TASCA, S.; CARLI, E.; DE LORENZI, D.; FURLANELLO, T.; CALDIN, M. Use of needle aspirates and flow cytometry for the diagnosis, classification, and immunophenotyping of canine lymphomas. Journal of Veterinary Diagnostical Invest, v. 17, n. 4 , p. 323-329, 2005

26 CIVARDI, G.; VALLISA, D.; BERTE, R.; GIORGIO, A.; FELICE, C.; CAREMANI, M.; CATURELLI, E.; POMPILI, M.; DE SIO, I.; BUSCARINI, E.; CAVANNA, L.; Ultrasound-guieded fine needle biopsy of the spleen: Hight clinical efficacy and low risk in a multicenter Italian study. American Journal of Hematology, v. 67, n. 2, p. 93-99, 2001.

27 FISHER, D. J.; NAYDAN, D.; WERNER, L. L.; MOORE, P. F. Immunophenotyping lymphomas in dogs: a comparison of results from fine needle aspirate and needle biopsy sample. Veterinary Clinical Patholology, v. 24, n. 4, p. 118-123, 1995

28 CARTER, R. F.; VALLI, V. E. O.; LUMSDEN, J. H. The cytology, histology and prevalence of cell types in canine lymphoma classified according to Nacional Cancer Institute Working Formulation. Cancer Journal of Veterinary Research, v. 50, n. 2, p. 154-164, 1986

29 LENNERT, K.; FELLER, A. C. Histopathology of nonHodgkin's lymphomas. 2. ed. Berlim: Springer-Verlag, 1990. 312 p.

30 CANIATTI, M.; ROCCABIANCA, P.; SCANZIZNI, E.; PALTRINIERI, S.; MOORE, P. F. Canine lymphoma: immunocytochemical analysis of fine needle aspiration biopsy. Veterinary Pathology, v. 33, n. 2, p. 204-212, 1996.

31 PARODI, A. L.; DARGENT, F.; CRESPEAU, F. Histological classification of canine malignant lymphomas. Zentralblatt für Veterinärmedizin. Reihe A, v. 35, n. 3, p. 178-192, 1988.

32 RALLIS, T.; KOUTINAS, A.; LEKKAS, S.; PAPADIAMANTIS, C. Lymphoma (malignant lymphoma, lymphosarcoma) in the dog. Journal of Small Animal Practice, v. 33, n. 12, p. 590-596, 1992. 